\title{
The Role of the Preparatory Year in the Selection of Engineering Specialization: A Case Study
}

\author{
https://doi.org/10.3991/ijep.v7i1.6342 \\ Omar S. Asfour \\ Islamic University of Gaza, Gaza, Palestine \\ oasfour@iugaza.edu.ps
}

\begin{abstract}
- at many universities, students who get enrolled at the faculty of engineering are required to study a preparatory year before they begin their specialized academic programs. This year includes several general engineering and basic science modules. It is claimed that this year gives students the required time and knowledge to decide on which engineering department they would select. This study aims to investigate this issue from students' and academics' points of view. Islamic University of Gaza (IUG) has been taken as a case study. The study carried out a survey that includes a questionnaire directed to the students and an interview directed to the academic staff. Results showed that the majority of students do not think they need an entire academic year to get a sufficient perception for the different engineering specialities. They think it would be better if they get specialized directly upon their entry to the university. This is also the recommendation of the academic staff. Despite the benefits claimed for the preparatory year, greater ones could be achieved if students are given the chance to get specialized earlier. This includes giving engineering departments more flexibility in the selection of the first year modules.
\end{abstract}

Keywords-Engineering education, academic programs, curriculum, preparatory year.

\section{Introduction}

Engineering is a profession that involves creative application of knowledge to deal with real-life problems. It has several branches, and requires special skills and carefully designed academic programs. These programs should provide students with the advanced, effective, and technology-based education that meets the market needs. Engineering curricula should be designed to assure provision of the technical understanding and problem-solving skills including problem analysis, investigation, design, communication, and management skills [1]. Duration of the bachelor degree of engineering varies between countries. For example, three-year duration is common in Europe, while five-year duration is common in the Arab countries.

Students who get enrolled at faculties of engineering have to select their engineering speciality. This decision is based on several factors. These factors include personal factors (such as personal skills), economic factors (such as admission fees and fu- 
ture income), and social factors (such as family preference) [2]. This means that universities have essential role to make students' selection consistent with the market requirements and the national development strategies. Universities vary in this regard. Some universities allow students to get specialized directly after obtaining GCSE. This depends on their total grades or their specific grade in the engineering-related modules. In some universities, students have to study a preparatory year before getting specialized.

During this year, students are expected to get some academic counselling regarding speciality selection. This year is composed of some basic science modules, and some basic engineering modules. Some standards in this regard recommend that engineering curriculum should comprise about $21 \%$ of its total credit hours as basic science modules, and another $21 \%$ as general engineering modules [3]. Some other standards recommend that engineering curriculum should include one year of a combination of college level mathematics and basic science modules appropriate to the discipline (biology, chemistry, and/or physics). This year is equivalent to the lesser of 32 credit hours or $25 \%$ of the total credits required for graduation [4].

In the Palestinian universities, bachelor of engineering is granted after the completion of a minimum of 158 credit hours [5]. A credit hour is equivalent to a 50 minutes instruction per a week of semester. Modules are distributed over two semesters per year. A summer semester may also be taken by students. The usual duration of BSc completion is five years. However, some students could complete their engineering programs earlier depending on the regulations concerning the maximum study load per semester. In the Islamic University of Gaza (IUG), the case study investigated in this paper, it is possible that engineering students complete their BSc in 4.5 years. The following modules are taught in the engineering preparatory year [6]:

- Basic science modules: This includes a total of 17 credit hours as follows: Calculus A and B (7 hrs.), Physics A and B ( 7 hrs.), and Chemistry (3 hrs.). Additional basic science modules are offered following the preparatory year depending on the selected engineering specialization.

- General engineering modules: This includes a total of 9 credit hours as follows: Introduction to Engineering ( $1 \mathrm{hr}$.), Engineering Graphics (2 hrs.), Technical English (3 hrs.), and Workshop Technology (1 hr.), and Introduction to Computing (2 hrs.).

In IUG, the grades earned by a student in this year are used to determine his/her eligibility for the engineering specialty that he/she selected by the end of the preparatory year. Although this made engineering specialty selection a competitive process, it overlooks the differences that exist between these specialties in terms of the required skills and knowledge. In contrast, some institutions adopted an assessment approach in which the grades earned by a student after the completion of the engineering preparatory year are not counted in the calculation of his/her cumulative GPA at the time of graduation [7].

There are nine Palestinian universities that grant BSc programs in engineering [8]. Engineering students at these universities have to take a preparatory year before getting specialized in one of the engineering branches. This is true for IUG too. Few 
exceptions only exist such as the Mechatronics program in Birzeit University in the West Bank [8]. Thus, this study aims to investigate the role of this preparatory year in helping students to choose their engineering specialization. This is carried out with reference to the Faculty of Engineering at IUG, Palestine. The study, however, does not discuss the modules offered in this year in terms of their content, but in terms of their role in guiding students to successfully choose their engineering specialization.

\section{Research Methods}

Academic education has three pillars: the student, the academic staff, and the curricula. It is clear that the concerned stakeholders here are students and academic staff members. Thus, a two-fold methodology has been adopted: a questionnaire directed to students, and a structured interview directed to the academic staff members. The questionnaire has been directed to two categories of IUG engineering students: students in the second semester of the preparatory year, and students who have got specialized in the different departments. The interview has been directed to the IUG Engineering Faculty council members. Results were qualitatively and quantitatively analysed.

The targeted population was about 500 students in the first questionnaire and about 2000 students in the second one. Considering a confidence level of $95 \%$, and a margin of error of $10 \%$, a sample size of 100 sampling units in the first case and 150 sampling units in the second one is estimated [10]. Thus, a total of 250 questionnaires were distributed in person using a proportional stratified random sampling method, where different sizes of engineering departments were considered. As for the interview, a total of eight structured interviews were conducted with the IUG Engineering Faculty council members. Description of the questionnaire and the interview are presented in the relevant sections below.

\section{Results and Discussion}

\subsection{Preparatory Year Students' Questionnaire}

This questionnaire is named Questionnaire A. A total of 100 questionnaires were distributed to the first level (preparatory year) students at IUG Faculty of Engineering. 60 questionnaires were distributed to male students, and 40 questionnaires were distributed to female students. This reflects their percentage in the targeted population (500 students). The questionnaire was based on five-point Likert scale, and included three sections as follows:

Section 1 is about students' perception for engineering speciality and the difference between its different specialities,

Section 2 is about the role of students' academic counselling in choosing engineering speciality, and

Section 3 is about the idea of speciality directly after the GCSE. In the first section, three statements were presented to students: 
1.1. I had a clear vision about the nature of engineering profession before getting enrolled at the University.

1.2. I had a clear vision about the different engineering specializations before getting enrolled at the University.

1.3. I do not think I need an entire year to gain a clear perception for the different engineering specialities.

Figure 1 shows the obtained results. It is clear in question 1.1 that a significant percentage of students $(70 \%)$ strongly agree or agree with the suggestion that they had a clear vision about the nature of engineering profession before getting enrolled at the University. Although it is not clear to which extent they understand the nature of engineering profession, this gives an indication that they have at least a general background in this regard. As for question 1.2, 44\% of students believe they had a clear vision about the nature of the different engineering specializations before getting enrolled at the University. About the third did not accept this statement, and about the quarter presented a neutral response.

This shows a relatively high uncertainty level among students regarding this issue ( $56 \%$ of students). In the previous two questions, no difference was observed between male and female students. As for question 1.3, 56\% of students do not feel they need an entire academic year to understand the difference between engineering specializations at the Faculty of Engineering. This point of view was presented by $72 \%$ of male students and by $33 \%$ of female students. On the other hand, $42 \%$ of students did not accept this statement $(26.7 \%$ of male students, and $65 \%$ of female students). This shows female students' interest in the preparatory year in general.

In Section 2, the following statements were questioned:

2.1. I feel that I have got sufficient academic counselling to help me choose my engineering specialization by the end of my first level study.

2.2. The nature of study in the preparatory year helped me to make my specialization decision.

2.3. It is possible to replace this counselling with other alternatives including consulting family and engineers.

Figure 2 shows the obtained results. In question 2.1, the issue of academic counselling is questioned. This refers to the guidance offered for students to help them to select their engineering speciality. This could be done either during the academic lectures or through personal contact between the student and his/her academic supervisor. 57\% of students do not feel that they had sufficient academic counselling to help them choose their engineering specialization during the preparatory year. About the third (36\%) believe that they had such counselling. Question 2.2 asked students whether they believe or not that the nature of their study in the preparatory year helped them to make their specialization decision. This question is more related to the content of the courses offered in this year and the acquired skills in this respect. Students are split here (39\% strongly disagreed or disagreed, $11 \%$ were neutral, and $50 \%$ strongly agreed or agreed). However, question 2.3 shows that the majority $(72 \%)$ believe that it is possible to replace the academic counselling in the preparatory year with other alternatives such as consulting of graduates and on-job engineers. 


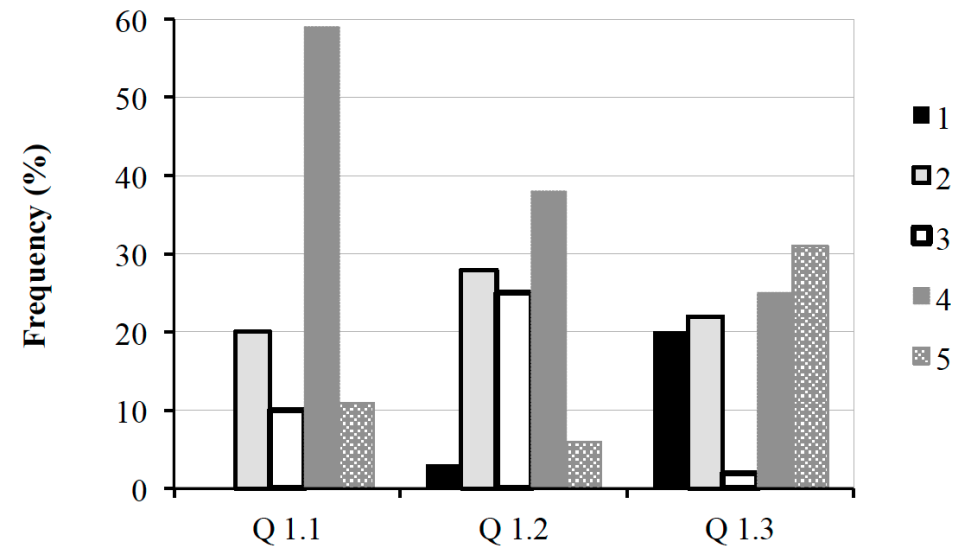

Fig. 1. Students' responses to the questions of Section 1 in Questionnaire A presented on a five-point Likert scale, where 1 is the least value

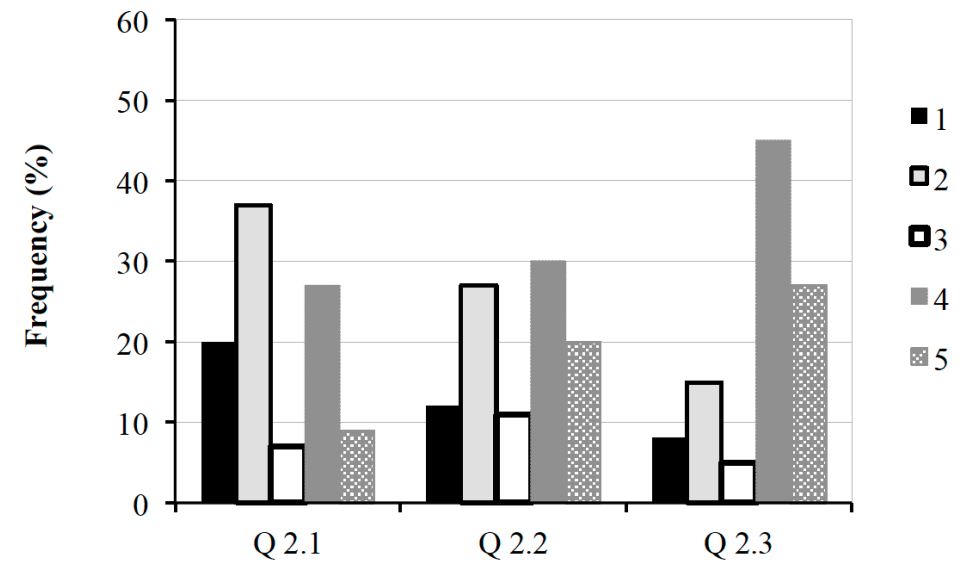

Fig. 2. Students' responses to the questions of Section 2 in Questionnaire A presented on a five-point Likert scale, where 1 is the least value

In Section 3, the following statements were questioned:

3.1. I think it would be better if I got specialized directly after my GCSE.

3.2. I think that getting specialized directly after the GCSE reduces students' confusion regarding engineering specialization selection.

3.3. I think that getting specialized directly after the GCSE prevents students from getting to know the other engineering disciplines.

Figure 3 shows the obtained results. It is clear in question 3.1 that $60 \%$ of students strongly agree or agree with the suggestion of getting specialized directly after the GCSE level. $38 \%$ of them strongly disagreed or disagreed, while only $2 \%$ were not sure. Question 3.2 shows that $57 \%$ of them believe that this reduces students' confusion regarding specialization selection. However, 33\% of students did not accept this statement. The third question, Question 3.3, was a verification one. Students' response 
was inconsistent with their previous answers. $50 \%$ of students said that getting specialized directly after the GCSE prevents students from getting to know the other engineering disciplines. $33 \%$ of students did not accept this statement, while the rest $(17 \%)$ were neutral.

This can be explained by looking at the detailed responses of male and female students. Figure 4 shows these responses. It is clear that the majority of male students (75\%) accept the suggestion of getting specialized directly after the GCSE level, while $37.5 \%$ of female students do not. Also, $32 \%$ of male students believe that this will prevent them from getting to know the other engineering disciplines offered at the Faculty, while $77.5 \%$ of female students have the same belief. This again shows female students' uncertainty regarding the selection of their engineering speciality.

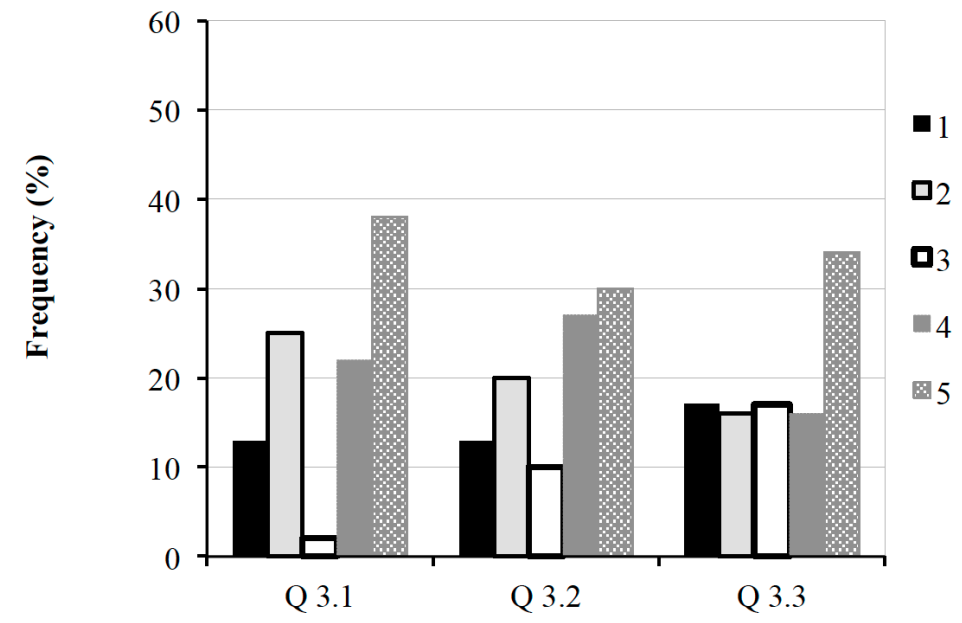

Fig. 3. Students' responses to the questions of Section 3 in Questionnaire A presented on a five-point Likert scale, where 1 is the least value

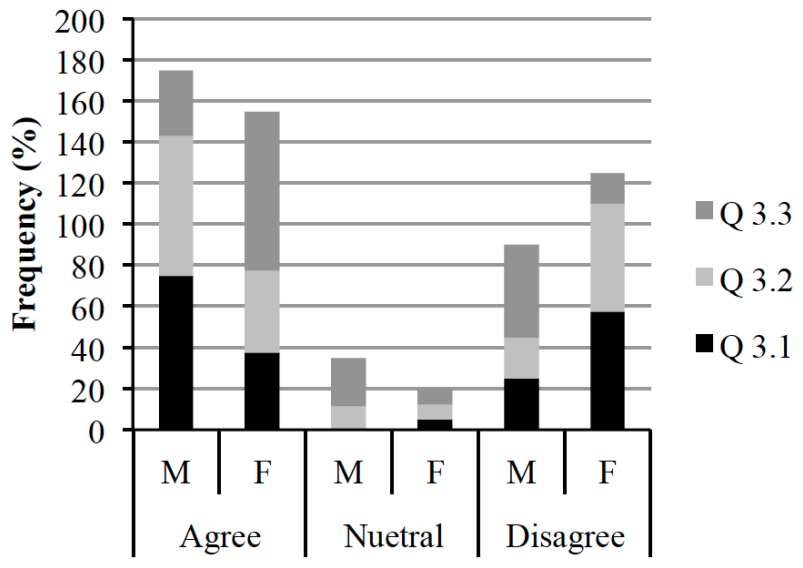

Fig. 4. Male and female students' responses to the questions of Section 3 in Questionnaire A 


\subsection{Specialized Students' Questionnaire}

This questionnaire is named Questionnaire B. This questionnaire was directed to students in the different departments of IUG Faculty of Engineering. A total of 150 questionnaires were distributed to the different departments in proportion to their size, i.e. number of enrolled students. Percentages of male and female students were also observed in the sampling process, where 90 questionnaires were distributed to male students, and 60 questionnaires were distributed to female students. The questionnaire was based on five-point Likert scale, and included three statements as follows:

1. I feel that I have received an appropriate academic guidance to help me choose my engineering specialization during my study at the preparatory year.

2. I think that the preparatory year is necessary for students to determine the specialization they want in the Faculty of Engineering.

3. I think it would be better if I have got specialized at the beginning of my study at the University (according to my GCSE result).

Figure 5 shows that $37 \%$ of students believe that they have received an appropriate academic guidance to help them choose the engineering specialization during the preparatory year, while majority of students $(55 \%)$ do not believe so. As for question Q2, 57\% of students accept that the preparatory year is necessary for students to determine the specialization they want, while $37 \%$ of them do not think so. This is again related to the observed disagreement between male and female students. Majority of female students $(67 \%)$ believe that the preparatory year is essential to help students selecting their specialization, while $50 \%$ of male students believe so.

Finally, $62 \%$ of students in question Q3 believe that it would be better if they got specialized directly after the GCSE level, while the third (32.5\%) disagreed with that. Table 1 shows a spread of the results presented in Figure 5 for the different departments at IUG Faculty of Engineering at time of the study. It can be noticed that results of the individual departments are consistent with the above-mentioned results at Faculty level. For example, students at the different departments believe that the prepara-

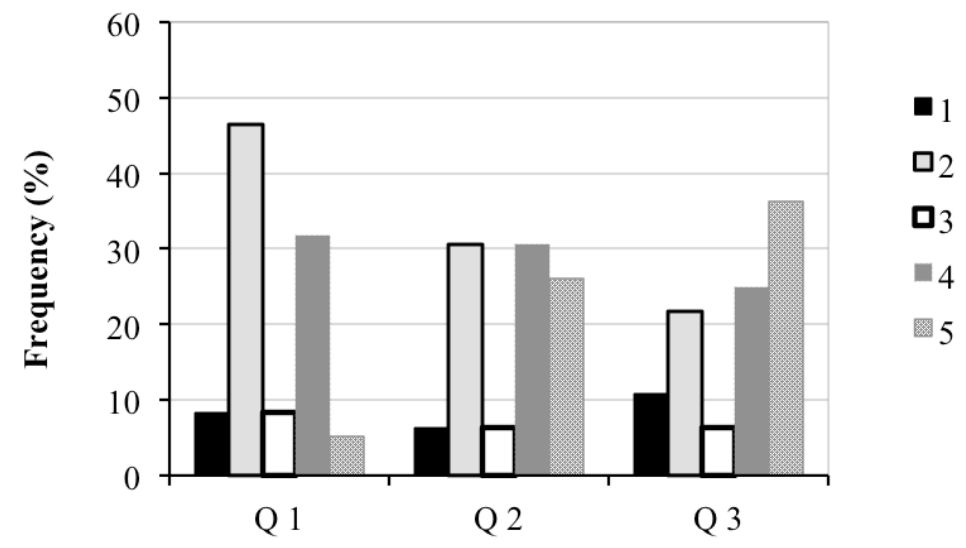

Fig. 5. Students' responses to the questions of Questionnaire B presented on a five-point Likert scale, where 1 is the least value 
Table 1. Students' responses to the questions of Questionnaire B presented for the different Departments

\begin{tabular}{|c|c|c|c|c|c|c|}
\hline Dept. & \multicolumn{3}{|c|}{ Civil Engineering } & \multicolumn{3}{c|}{ Architectural Engineering } \\
\hline Q. & Agree & Neutral & Disagree & Agree & Neutral & Disagree \\
\hline 1 & 51.4 & 8.6 & 40 & 31 & 3.4 & 65.5 \\
\hline 2 & 57.2 & 5.7 & 37.2 & 48.2 & 13.8 & 37.9 \\
\hline 3 & 65.7 & 11.4 & 22.8 & 72.4 & 3.4 & 24.1 \\
\hline Dept. & \multicolumn{3}{|c|}{ Electrical Engineering } & \multicolumn{3}{c|}{ Computer Engineering } \\
\hline Q. & Agree & Neutral & Disagree & Agree & Neutral & Disagree \\
\hline 1 & 42.9 & 14.3 & 42.9 & 23.3 & 3.3 & 73.3 \\
\hline 2 & 64.3 & 7.1 & 28.6 & 53.4 & 3.3 & 43.3 \\
\hline 3 & 67.9 & 3.6 & 28.6 & 53.3 & 10 & 36.7 \\
\hline Dept. & \multicolumn{7}{|c|}{ Environmental Eng. } & \multicolumn{3}{|c|}{ Industrial Engineering } \\
\hline Q. & Agree & Neutral & Disagree & Agree & Neutral & Disagree \\
\hline 1 & 40 & 15 & 45 & 26.7 & 6.7 & 66.6 \\
\hline 2 & 65 & 0 & 35 & 53.4 & 6.7 & 40 \\
\hline 3 & 45 & 0 & 55 & 53.4 & 6.7 & 40 \\
\hline
\end{tabular}

tory year in general is necessary for students to determine the specialization they want in the Faculty of Engineering (Question 2). However, significant percentage of them believes that it would be better if they got specialized directly after the GCSE level (Question 3). This is more significant for the Architectural Engineering students, because their speciality is possibly the least one that benefit from the basic science modules offered in the preparatory year.

\subsection{The Interview}

An interview has been carried out with the IUG Engineering Faculty council members. These members were selected because they are in charge of study plans preparation at IUG Faculty of Engineering. Five statements were questioned as follows:

1. I think that the preparatory year is essential to help students choose their engineering specialization.

2. I think that academic counselling given to students in this year helps them choose their specialization.

3. I think that the academic curriculum of this year is essential and helps students choose their specialization.

4. I recommend that new students at Faculty of Engineering get specialized:

- Option 1: After the completion of the preparatory year.

- Option 2: After the completion of the first semester of the preparatory year.

- Option 3: Directly after completion of GCSE level.

- Option 4: After completion of either the GCSE level or the preparatory year (a hybrid system).

Figure 6 shows the obtained results of the first three questions. It is clear that majority of the interviewees (63\%) do not believe that the preparatory year is essential to help students choose their specialization, while $37 \%$ believe so. The interviewees who 


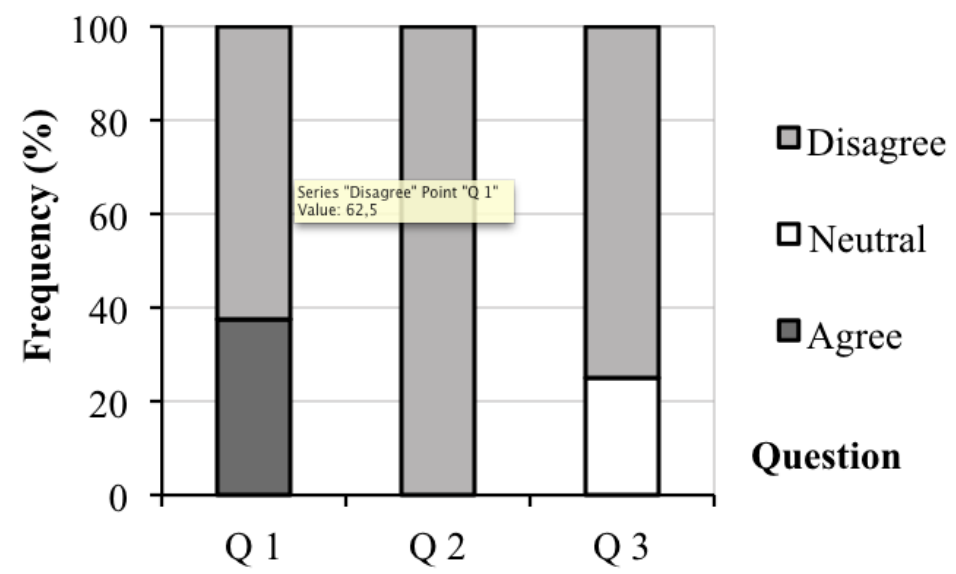

Fig. 6. Interviewees' responses to the first three questions of the structured interview presented on a three-point Likert scale

disagreed justified their disagreement with their belief that the trend in education today is towards specificities not generalities. Allocating an entire academic year as a general one restricts the ability of the Faculty departments to develop their study plans. This is true considering the rapid growth of engineering knowledge and the resulting novel technologies and design products [11]. Furthermore, the role of basic education and media is essential here, which means that students could gain good background about their future professions easily. On the other hand, the interviewees who agreed on the importance of this preparatory year said that students in this stage have no clear vision about which speciality they have to select, and may go for the recommendations of their families and friends without any deep investigation.

In the second question, there is a consensus to disagree with the statement saying that academic counselling given to students in their preparatory year helps them choose their speciality. The interviewees mentioned that this counselling is limited to one module (Introduction to Engineering), for which one credit hour is allocated. They also mentioned that there is a need for more guidance including workshops and field visits. In the third question, the majority (75\%) disagreed with the statement saying that the academic curriculum of this year is consistent with the aim of helping students choose their specialization. When they were asked to justify this, they said that the nature of modules in this year do not give students a clear perspective about the different available engineering specialities, which may mislead them in the selection of their academic programs.

The fourth question asked the interviewees about the possible options that could be implemented to help students to get specialised at the Faculty of Engineering. Four options were suggested. The first one was to continue using the current system, i.e. the preparatory year system. Results showed that none of the interviewees believe that the current system should be implemented any more (option 1). This is related to some differences that exist between the offered engineering programs in terms of their needs of the general science and engineering modules offered in this year. For exam- 
ple, the needs of the electrical engineering program when compared to the needs of the civil engineering program. However, the interviewees had different opinions regarding the most appropriate alternative (options 2, 3, and 4).

Some of the interviewees $(25 \%)$ believe that students should get specialized after the completion of the first semester of the preparatory year (option 2). Majority of them (63\%) recommended that students should get specialized directly after the completion of GCSE level (option 3). Finally, only $12 \%$ of them recommended a hybrid system that gives students the ability to get specialized after completion of the GCSE level or the preparatory year (option 4). When these findings are triangulated with the findings of the students' survey (Section A and B), it is possible to notice that option 2 (to get specialized after the completion of the first semester) and option 4 (to get specialized after the completion of either the GCSE level or the preparatory year) form balance suggestions that satisfy the different opinions and concerns discussed in this study.

\section{Conclusion}

This study aimed to investigate the necessity of the preparatory year in helping students at the faculty of engineering to select their speciality by the end of this year. Faculty of Engineering at the Islamic University of Gaza was selected as a case study. This issue was investigated from students' and academic staff's points of view. Two questionnaires in addition to an interview were carried out. Results generally showed that despite the benefits claimed for this preparatory year, there is a need to develop the currently implemented system. $56 \%$ of students at the preparatory year do not feel they need an entire academic year to understand the differences between engineering specializations. In addition, $63 \%$ of the interviewees do not believe that this entire year is essential to help students choose their engineering specialization.

Triangulation of the results showed that the suggestion that students should get specialized directly after obtaining the GCSE was recommended by the majority of the interviewees (63\%), the majority of students at advanced levels $(62 \%)$, and the majority of students at the preparatory year $(60 \%)$. More support to this suggestion was presented by male students who form about two thirds of the Faculty of Engineering. Therefore, the study suggests that students may be given the chance to get specialized by the end of their first semester at the University. This gives them sufficient time to get to know the different engineering specializations, and gives the different academic departments more flexibility in the design of their academic programs.

\section{$5 \quad$ References}

[1] Engineers Canada Accreditation Board. 2015 Accreditation Criteria and Procedures. Available at $<\underline{\text { http://www.engineerscanada.ca/sites/default/files/accreditation criteria pro }}$ cedures 2015.pdf $>$ [29 Mar. 2016]. 
[2] M. Ana-Andreea, N. M. Liviu, and M. C. Alina, "Factors of influence in the choice of a higher education specialization in Romania," Procedia - Social and Behavioral Sciences, vol. 84, pp. 1041 - 1044, 2013. https://doi.org/10.1016/j.sbspro.2013.06.695

[3] NAQAAE, National Authority for Quality Assurance and Accreditation for Education. National academic reference standards (NARS) for engineering. Available at $<$ http://www.must.edu.eg/arabic/Quality/pdf/standards/Engineering 7-4-2009.pdf $>$ [2 Apr. 2016].

[4] ABET, Criteria for Accrediting Engineering Programs, 2016 - 2017. Available at $<\underline{\text { http://www.abet.org/accreditation/accreditation-criteria/criteria-for-accrediting-engineeri }}$ ng-programs-2016-2017/\#curriculum > [6 Oct. 2016].

[5] AQAC, Palestinian Accreditation and Quality Assurance Commission, Guidelines about credit hours and their distribution in the BSc programs (Arabic). Available at $<$ http://www.aqac.mohe.gov.ps/home/policies and instructions/> [29 Mar. 2016].

[6] IUG Faculty of Engineering, First level study plan. Available at $<$ http://eng.iugaza.edu.ps $>$ [6 Oct. 2016].

[7] M. Aoudia, and D.A. Abu-Alqahsi, "Curriculum Redesign Process for an Industrial Engineering Program Seeking ABET," International Journal of Engineering Pedagogy, vol. 5, no. 3, pp 45-52, 2015. https://doi.org/10.3991/ijep.v5i3.4670

[8] AQAC, Palestinian Accreditation and Quality Assurance Commission, Accredited academic programs (Arabic). Available at $<$ http://www.aqac.mohe.gov.ps/home/accreditedacademic-programs/> [30 Mar. 2016].

[9] Birzeit University, Faculty of Engineering and Technology webpage. Available at $<$ http://www.birzeit.edu/ar/faculties/engineering-technology $>$ [30 Mar. 2016]

[10] M. Dhamen, Fundamentals of scientific research. Amman: Dar Al-Massira, 2007.

[11] I. Belski, R.Adunka, and O. Mayer, "Educating a Creative Engineer: Learning from Engineering Professionals," Procedia CIRP, vol. 39, pp. 79 - 84, 2016. https://doi.org/10.1016/j.procir.2016.01.169

\section{Author}

Dr. Omar Asfour is an Associate Prof. at Dept. of Architecture, Faculty of Engineering, Islamic University of Gaza, Palestine (e-mail: oasfour@ iugaza.edu.ps; o.asfour@hotmail.com).

Article submitted 16 October 2016. Published as resubmitted by the author 14 December 2016. 